Der Kern des Cometen blieb' also in einiger Entfernung vom Vergleichstern; es fehlen mir genauere Zeichnungen der Hülle des Cometen um entscheiden zu können, ob die Aenderungen in den gemessenen Abständen der beiden Sterne in Beziehung damit stehen.

Juni 13. Beobachtung durch die Nähe eines Sterns sehr erschwert; Comet hat starke sternartige Verdichtung. - Juni r 5. Comet recht hell. Schweif mit dem kleinen Cometensucher nur wenig weit zu verfolgen. - Juni 24. Comet recht hell, sternartige Verdichtung. - Juli $\times 6$. Comet schon bedeutend schwächer.

\section{Comet Winnecke 1892 IV.}

1892 Mai 26. Comet mit halbem Objectiv sehr schwach, Beobachtung äusserst schwierig. - Mai 30. Sehr schwierige Messung, grosse ausgedehnte Nebelmasse. Von diesem Tage an wurde das neue Ocular von 50 facher Vergrösserung bei Cometenbeobachtungen beständig benutzt; vorher Ioofache Vergrösserung. - Juni 13. Comet bei der hellen Beleuchtung des Himmels etwas schwach. -
Juni 15. Himmelsgrund sehr hell. - Juni 24. Comet recht hell, sternartige Verdichtung.

\section{Comet 1892 III (Holmes).}

1892 Nov. I I. Grosse kreisförmige Nebelmasse mit nahe centraler Verdichtung, Luft sehr dunstig, Himmel zum Theil bedeckt. - Nov. 16. Siehe Bemerkung in A. N. 3130. Nov. 19. Beobachtung sehr schwierig, Luft dunstig. - 1893 Jan. 19 7 $1 / 2$ Uhr M. Z. Die Abweichung meiner Helligkeitsschätzung (A. N. 3546) gegen andere erklärt sich dadurch, dass nicht die Helligkeit der ganzen Erscheinung an sich, sondern nur die des Kerns allein mit benachbarten Sternen der Bonner Durchmusterung verglichen wurde.

Diejenigen Vergleichsterne, für welche keine neueren Bestimmungen bekannt sind, sind in das Beobachtungsprogramm für den Göttinger Meridiankreis aufgenommen und die Oerter sollen veröffentlicht werden, sobald das durch schlechtes Wetter und Aenderungen des Instruments sehr zurückgebliebene Material vervollständigt und berechnet sein wird.

Göttingen 1893 Febr. 18.

Wilhelm Schur.

\title{
Beobachtungen des Cometen 1892 Ill (Holmes)
}

angestellt mit dem Zehnzöller der Sternwarte zu Genf.

\begin{tabular}{|c|c|c|c|c|c|c|c|c|c|c|}
\hline 1893 & I. Z. Genf & $\Delta a$ & $\Delta \delta$ & gl. & $\alpha$ app. & $\operatorname{og} p .4$ & $\delta$ app. & $g p .4$ & Red.ad l.app. & * \\
\hline $\begin{array}{r}3 \\
6 \\
13 \\
14 \\
15 \\
17 \\
18\end{array}$ & $\begin{array}{lrrr}9^{b} & 9^{m} & 0^{2} \\
9 & 2 & 57 \\
9 & 56 & 45 \\
9 & 10 & 45 \\
9 & 4 & 37 \\
8 & 26 & 20 \\
9 & 7 & 43\end{array}$ & $\begin{array}{rr}-0^{m} & 41: 24 \\
-1 & 6.46 \\
+0 & 5460 \\
+2 & 12.81 \\
-1 & 53.66 \\
-1 & 7.14 \\
+0 & 6.54\end{array}$ & 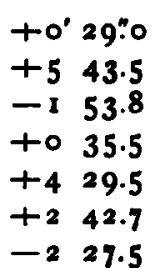 & \begin{tabular}{|c|}
12.8 \\
18.10 \\
18.6 \\
18.6 \\
18.10 \\
12.7 \\
20.10
\end{tabular} & $\begin{array}{rrr}I^{\mathrm{h}} & 47^{\mathrm{m}} & 3 ! 65 \\
1 & 51 & 37.07 \\
2 & 2 & 39.63 \\
2 & 4 & 9.5 \mathrm{I} \\
2 & 5 & 46.72 \\
& & - \\
2 & 10 & 38.84\end{array}$ & $\begin{array}{l}9.669 \\
9.808 \\
9.675\end{array}$ & $\begin{array}{rrr}+33^{\circ} & 50^{\prime} & 26.0 \\
+33 & 55 & 3.8 \\
+34 & 7 & 28.4 \\
+34 & 9 & 38.0 \\
+34 & 11 & 53.6 \\
& - & \\
+34 & 19 & 6.1\end{array}$ & $\begin{array}{l}85 \\
86 \\
86 \\
24 \\
18 \\
64\end{array}$ & $\begin{array}{l}-0.95+8.2 \\
-0.97+8.1 \\
-1.01+8.0 \\
-1.02+8.0 \\
-1.03+8.0 \\
-1.04+8.0 \\
-1.04+8.0\end{array}$ & $\begin{array}{l}6 \\
7\end{array}$ \\
\hline
\end{tabular}

Mittere Oerter der Vergleichsterne fur r893.0.

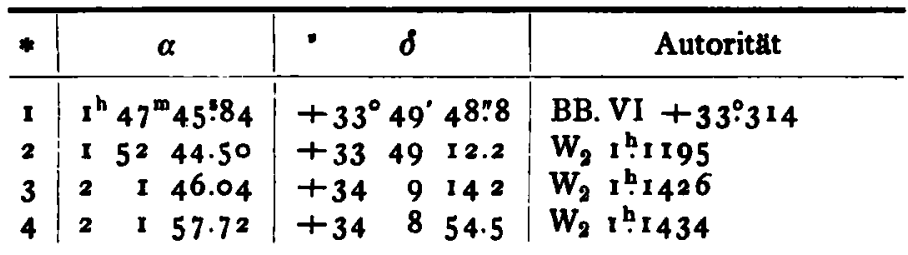

\begin{tabular}{|c|c|c|c|}
\hline$*$ & $a$ & $\delta$ & Autorităt \\
\hline $\begin{array}{l}5 \\
6 \\
7\end{array}$ & $\begin{array}{lcc}2^{b} & 7 \mathbf{D}^{4} 1: 39 \\
2 & 10 & 7 \\
2 & 10 & 33.34\end{array}$ & $\begin{array}{l}+34^{\circ} 7^{\prime} 16^{\prime \prime} \mathrm{x} \\
+3414 \\
+342125.6\end{array}$ & $\begin{array}{l}\text { Paris } 275^{6} \\
\text { Anonyma } 10^{\mathrm{m}} \\
\text { BB. VI }+34^{\circ} 405\end{array}$ \\
\hline
\end{tabular}

Bemerkungen.

Febr. 3. Der Comet hat heute einen ca. $5^{\circ}$ - langen Schweif, der aber sehr schwach ist. Coma ziemlich gut sichtbar, aber ohne Spur eines Kerns. Einstellung daher schwierig. Zuletzt wird der Comet äusserst schwach wegen Mondschein und Dunst.

Febr. 6. Der Comet hat die gleiche Form beibehalten.

Febr. I3. Ein Stern $\mathbf{I}^{\mathrm{m}}$ ist Anfangs an der Stelle des abwesenden Kerns, so dass man hätte glauben können, det Comet habe wieder an Helligkeit zugenommen. Nachher stört er sehr die Beobachtungen. Bestimmung unsicher.
Febr. 14. Gleicher Fall wie gestern mit einem Stern $12^{\mathrm{m}}-13^{\mathrm{m}}$. AR. wahrscheinlich um $0: 2$ bis $0 ? 3$ zul vermehren, Decl. um ein paar Bogensecunden.

Febr. 18. Der Comet hat dasselbe generische Aussehen wie an 3. Febr. beibehalten. Die Abwesenheit einer Condensation hat sämmtliche Beobachtungen etwas unsicher gemacht.

Febr. 20. Nach Untergang des Mondes vermuthe ich den Cometen; er ist aber viel zu schwach um beobachtet zu werden. Himmel ein wenig dunstig. 